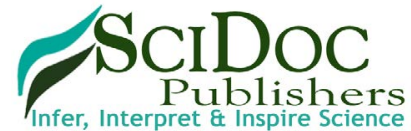

International Journal of Magnetism \& Nuclear Science (IJMN)

ISSN: $2577-4387$

\title{
Activation Calculation and Analysis for CFETR Blanket
}

Review Article

Jiang $\mathrm{S}^{1}$, Chen $\mathrm{Z}^{1 *}, \mathrm{Xu} \mathrm{XG}^{1,2}$

${ }^{1}$ School of Nuclear Science and Technology, University of Science and Technology of China, China.

${ }^{2}$ Rensselaer Polytechnic Institute, Troy NY, USA.

\section{Abstract}

With a Monte Carlo code MCNPX and an activation calculation code FISPACT-2007, nuclear heart, radioactivity and shutdown dose rate for the breeding blanket of China fusion engineering test reactor (CFETR) have been calculated. The calculation results show that the total radioactivity is $2.34 \times 10^{19} \mathrm{~Bq}$ at shutdown after one year operation and the total radioactivity is $7.98 \times 10^{18} \mathrm{~Bq}$ which is $12.1 \%$ of the original radioactivity. Until the cooling time come to 2.6 years, 25.2 years and 46.4 years, respectively, tritium breeding material, neutron multiplier material and structure material can be remotely operated. The results show that there isn't serious environmental issue.

Keywords: CFETR; Monte Carlo Method; Nuclear Heat; Radioactivity; Shutdown Dose Rate.

\section{Introduction}

The main objective of the Chinese Fusion Engineering and Test Reactor (CFETR) is to demonstrate and realize tritium selfsufficiency breeding. The design, which is based on the tokamak approach with superconducting magnet technology, is currently undergoing the engineering conceptual design by the China National Integration Design Group for Magnetic Confinement Fusion Reactor of China. Other main missions include 50$200 \mathrm{MW}$ fusion power, $30 \% \sim 50 \%$ of duty cycle time or burning time [1-3].

For the design of CFETR, the breeding blanket is quite significant. The breeding blanket not only has to take the heat and power generated by plasma out under normal or abnormal situation, but also its tritium breeding ratio (TBR) has to be larger than 1.2 to meet the design requirement. What's more, the superconducting coils are under the protection of the breeding blanket from radiation damage. During the normal operation of CFETR, structural material, neutron multiplier material and tritium breeding material will generate many radioactive nuclides including tritium. Therefore, for the breeding blanket, it's quite important to calculate and analyze the radioactivity of source terms for material selection of blanket, and environmental safety.

\section{Methodology}

Because the neutron angular distribution is isotropic in magneticconfinement fusion, the neutron source's energy distribution can be described with Gaussian spectrum and neutrons' average energy is $14.1 \mathrm{MeV}$ [4]. For position distribution, it's a twodimensional Gaussian distribution looking from the plasma cavity cross section shown in Figure 1.

Assuming that CFETR is shut down after one year operation with full power (200MW), the neutron wall loading is set as $0.5 \mathrm{MW} \bullet$ $\mathrm{m}^{-2}$. Of course, the results accordingly are the upper limit which will provide a conservative estimate for safety analysis [5].

During our research, two main software packages: Monte Carlo code MCNPX [6] and the FISPACT code for activation analyses were used. Low energy standard structure: VITAMIN-J (175) [7] was choose for activation calculation. The calculation followed two main steps: (1) Neutron transport simulation was performed using the MCNPX Monte Carlo code to obtain spatial distribution of the neutron flux spectra in all blanket layers. (2) The FISPACT activation code carried out a series of calculations, such as decay gamma source calculation, total activity calculation [8]. 10 million particles were tracked by MCNPX code and the statistical error of neutron fluence in important cells was controlled below $2 \%$.

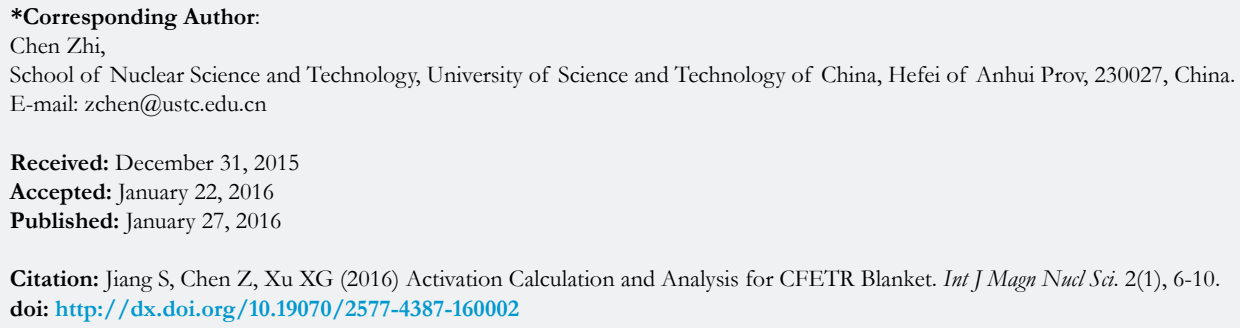

Copyright: Chen $Z^{\circ}$ 2016. This is an open-access article distributed under the terms of the Creative Commons Attribution License, which permits unrestricted use, distribution and reproduction in any medium, provided the original author and source are credited. 
Figure 1. The source energy distribution is according to the R-Z distribution.

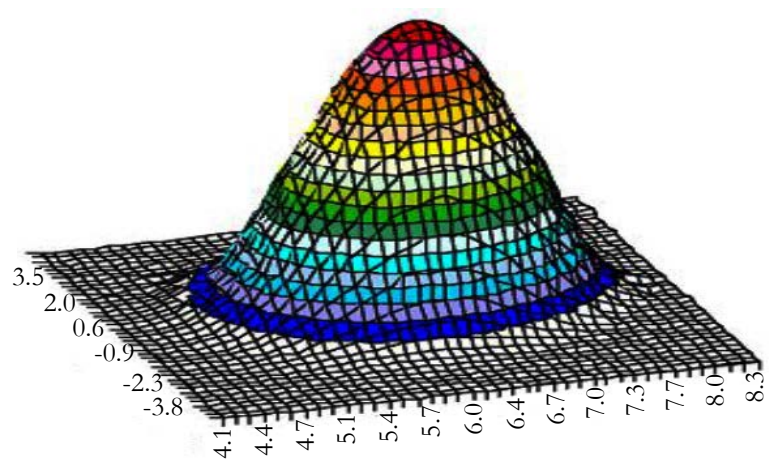

The nuclear data for the neutronics analyses describing all physical interactions were taken from the FENDL3.0 database. Activation cross section data for the FISPACT analyses were taken from the EAF-2007 evaluation.

\section{Geometric model and material arrangement}

A graphical display of the CAD model of CFETR is shown in Figure 2, Figure 3 presents the preliminary engineering dimension of CFETR [1].

According to the physics parameters and engineering data obtained from China National Integration Design Group, we established a simplified two-dimensional geometric model of CFETR for neutronic analysis. Figure 4 shows the two-dimensional schematic diagram of breeding blanket.

The selection of material is very important. LAFS (Low Ferrite Steel) was chosen for structure material. LAFS won't generate long life induced radioactivity under irradiation of high energy neutrons and it meets engineering requirements of blanket. $\mathrm{Li}_{4} \mathrm{SiO}_{4}$ was used as tritium breeding material and Be was used as neutron multiplier material. The performance of these materials are largely influenced by their purity and other contained trace elements [9]. Table.1 shows the materials and their elements' percentage.

\section{Results and Analysis}

\section{Tritium breeding ratio (TBR) and radioactivity}

The calculation of TBR was realized through counting multiplier card (FM). According to its definition, the valve of total amount of tritium generated in each neutron reaction is TBR. According to the results, TBR of the breeding blanket was 1.359 which meet the design requirement.

We chose three cells of inner breeding blanket from the inside out along the radial direction. According to the coordinate system set in Figure 4, the corresponding central point's abscissa value of cell 101 , cell 103 and cell 106 was $396 \mathrm{~cm}, 390 \mathrm{~cm}, 380 \mathrm{~cm}$, respectively. The corresponding three neutron energy spectrums were shown in Figure 5 which told us that the tendency of distribution of all the cells' neutron energy spectrums was moving down along the radial direction from the inside out.

Structural material, neutron multiplier material and tritium breeding material would generate many radioactive nuclides under irradiation of high energy neutrons including tritium. Figure 6 showed the radioactivity (in $\mathrm{Bq}$ ) as a function of the cooling time for different material. The total radioactivity of breeding blanket changed gently at the beginning of shutdown and the valve declined quickly after one year. When CFETR just shut down, the total radioactivity of breeding blanket was $6.61 \times 10^{19} \mathrm{~Bq}$. One year later, the total radioactivity declined to $2.34 \times 10^{19} \mathrm{~Bq}$. When cooling time reached ten years, the corresponding value was only $7.98 \times 10^{18} \mathrm{~Bq}$ which was $12.1 \%$ of initial value.

During the first year of shutdown, the total radioactivity of breeding blanket was mainly affected by structural material LAFS which mainly generated the following nuclides: ${ }^{56} \mathrm{Mn}\left(T_{1 / 2}=2.582 \mathrm{~h}\right),{ }^{55} \mathrm{Fe}\left(T_{1 / 2}=2.735 \mathrm{~h}\right),{ }^{187} \mathrm{~W}\left(T_{1 / 2}=23.85 \mathrm{~h}\right)$ and ${ }^{51} \operatorname{Cr}\left(T_{1 / 2}=27.7 \mathrm{~d}\right)$. Between 1 year and 200 years after shutdown, the total radioactivity was mainly affected by tritium breeding material $\mathrm{Li}_{4} \mathrm{SiO}_{4}$ which generated ${ }^{3} \mathrm{H}\left(T_{1 / 2}=12.33 \mathrm{a}\right)$ emitting $\beta$-particle of low energy. Because $\beta$ ray could be easily blocked, the ${ }^{3} \mathrm{H}$ wouldn't cause bad effect on radiation protection. 200 years later, ${ }^{14} \mathrm{C}\left(T_{1 / 2}=5730 \mathrm{a}\right)$ and ${ }^{94} \mathrm{Nb}\left(T_{1 / 2}=20000 \mathrm{a}\right)$ were the dominant radioactive nuclides generated in LAFS which affected the total radioactivity mainly again. In conclusion, there weren't long life radionuclides except ${ }^{3} \mathrm{H}$ generated in CFETR breeding blanket and it would be conductive to deal with nuclear waste [10].

\section{Dose rate analysis after shutdown}

A typical cell in breeding blanket whose neutron fluence was highest was chosen for calculation to demonstrate the shutdown dose rate as a function of the cooling times.

Figure 7. showed the specific information of shutdown dose rate of this typical cell in $10^{6}$ years. Structural material had a highest contribution to the whole dose rate. According to the criterion of remote operation for recycling $\left(10 \mathrm{mSv} \bullet \mathrm{h}^{-1}\right)$ [11], Until the cooling time come to 2.6 years, 25.2 years and 46.4 years, respectively, tritium breeding material, neutron multiplier material and structure material can be remotely operated.

\section{Nuclear heat}

When source neutrons pass through the breeding blanket, energy will be deposited by interaction directly or indirectly. The accumulated energy is nuclear heat and its simulation result would provide reference for thermo technical analysis. Figure 8. and Figure 9. respectively presented the thermal power as a function 
Figure 2. The vertical cross section representation of CFETR.

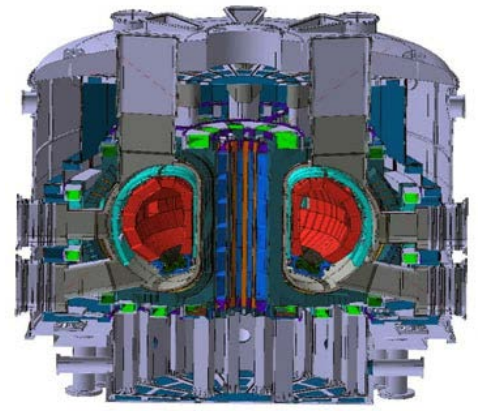

Figure 3. Engineering dimension of CFETR under preliminarily conceptual design.

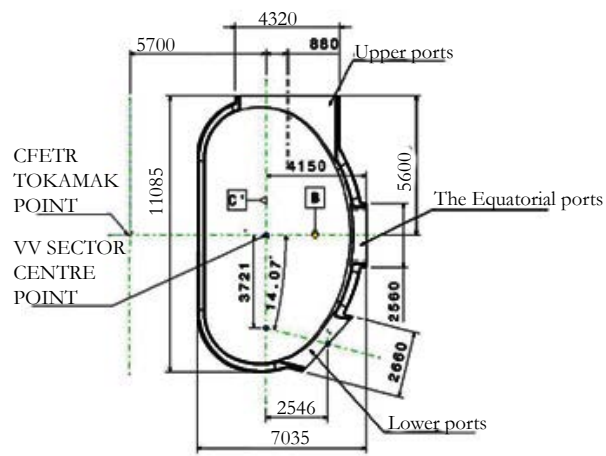

Figure 4. The two-dimensional schematic diagram of breeding blanket. Both inner and outer breeding blankets were divided into five layers.

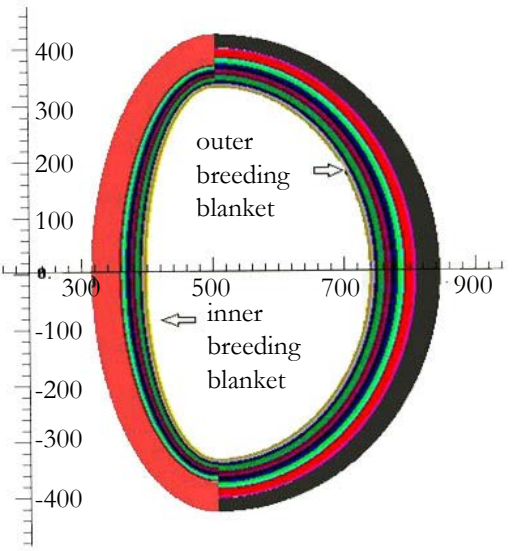

Table 1. Materials and their elements' percentage (wt $\%)$.

\begin{tabular}{|c|c|c|c|c|}
\hline Element & LAFS & $\mathbf{B e}$ & $\mathbf{L i}_{4} \mathbf{S i O}_{4}$ & $\mathbf{H e}$ \\
\hline $\mathrm{Fe}$ & 88.92000 & 0.04350 & 0 & 0 \\
\hline $\mathrm{Cr}$ & 9.51700 & 0.00600 & 0 & 0 \\
\hline $\mathrm{Mn}$ & 0.42750 & 0 & 0 & 0 \\
\hline $\mathrm{W}$ & 0.45620 & 0 & 0 & 0 \\
\hline $\mathrm{Si}$ & 0.01999 & 0.01000 & 11.15244 & 0 \\
\hline $\mathrm{V}$ & 0.21950 & 0.00200 & 0 & 0 \\
\hline $\mathrm{C}$ & 0.39140 & 0.08100 & 0 & 0 \\
\hline $\mathrm{O}$ & 0.03000 & 0.05120 & 44.38554 & 0 \\
\hline $\mathrm{Ta}$ & 0.02225 & 0 & 0 & 0 \\
\hline $\mathrm{Ni}$ & 0.01905 & 0 & 0 & 0 \\
\hline $\mathrm{He}$ & 0 & 0 & 0 & 100 \\
\hline $6 \mathrm{Li}$ & 0 & 0 & 40.01487 & 0 \\
\hline $7 \mathrm{Li}$ & 0 & 0 & 4.44714 & 0 \\
\hline $\mathrm{Be}$ & 0 & 99.8072 & 0 & 0 \\
\hline \multicolumn{5}{|c}{} \\
\end{tabular}


Figure 5. A presentation of three chosen cells' neutron spectrums along the radial direction from the inside out.

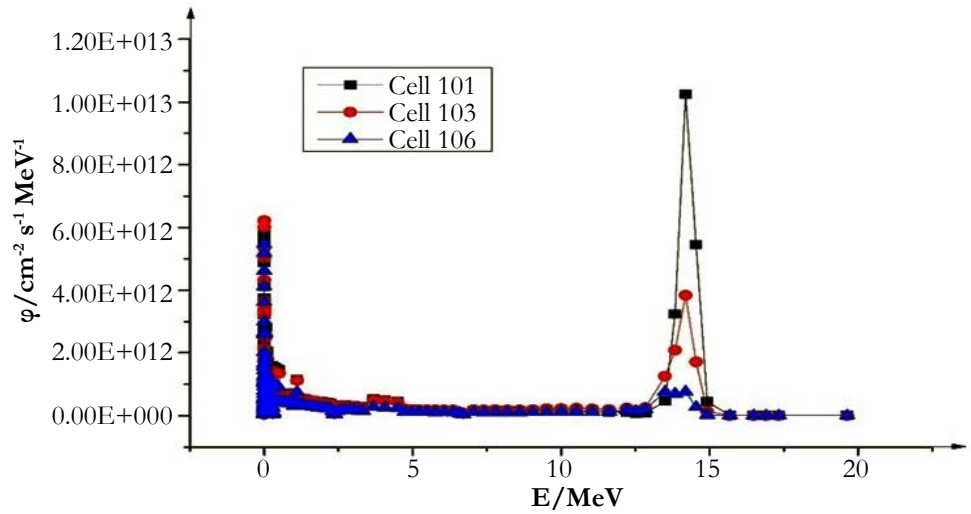

Figure 6. The radioactivity (in $\mathrm{Bq}$ ) as a function of the cooling time for different material.

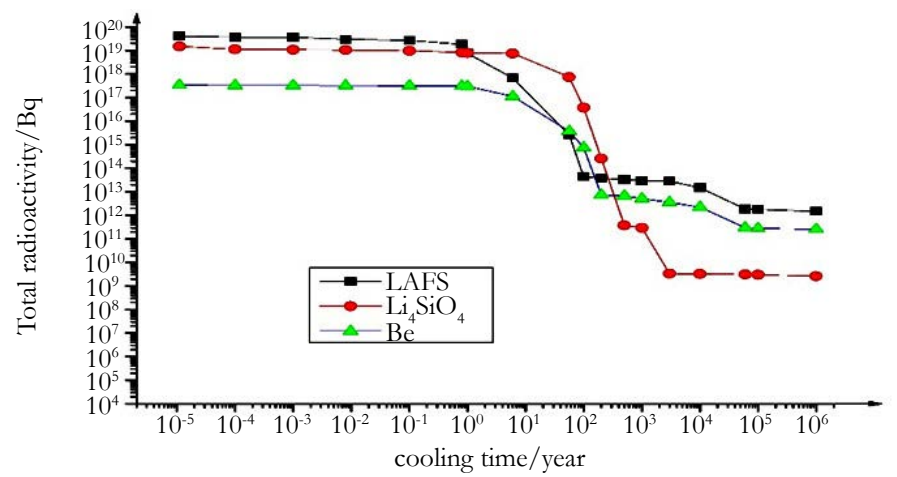

Figure 7. The shutdown dose rate as a function of the cooling times in a typical cell.

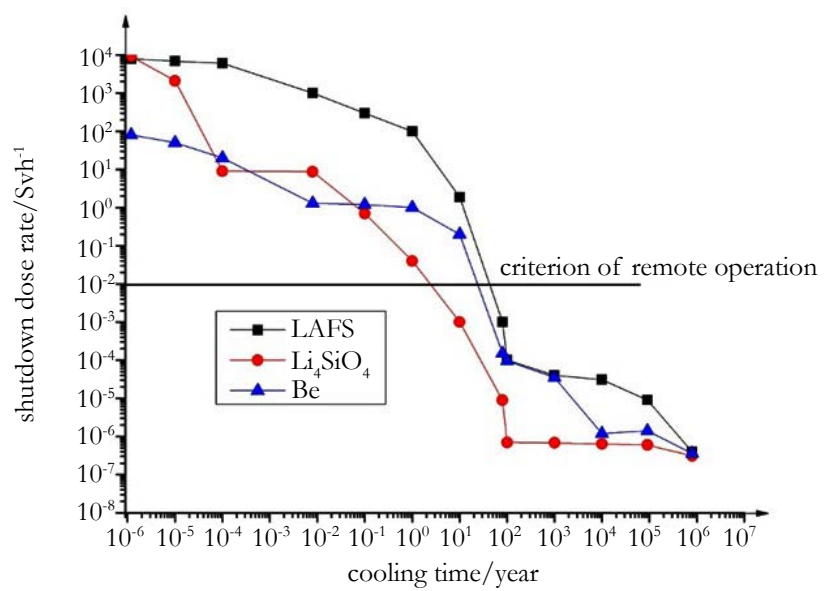

Figure 8. The thermal power as a function of radial distance of inner breeding blanket.

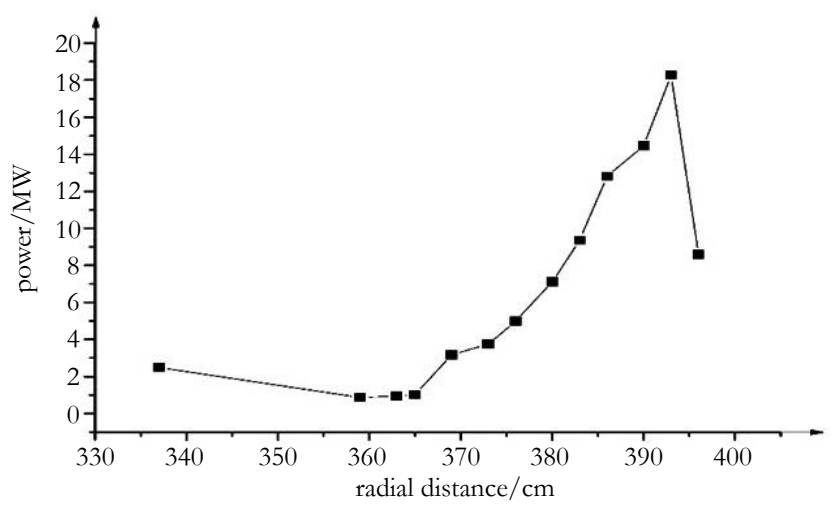


Figure 9. The thermal power as a function of radial distance of outer breeding blanket.

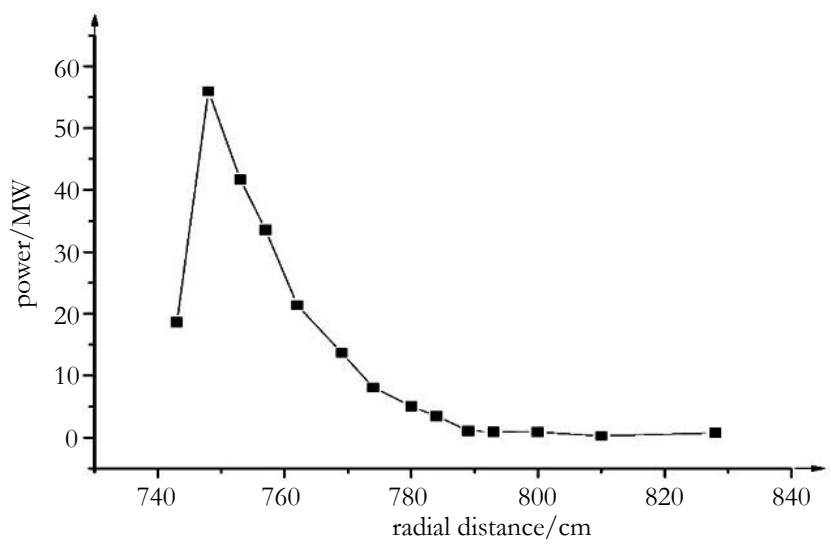

of radial distance of both inner and outer breeding blankets under steady operation. The points' positon information in Figure 8 and Figure 9. could be found in Figure 4.

According to calculation result, the heat was mainly deposited in the breeding area of blanket. Since the first wall was facing plasma directly, its thermal power was also high and coolant circuit should be taken into consideration. Comparatively speaking, the thermal load of outer breeding blanket was higher than the thermal load of inner breeding blanket. The tendency of thermal power was declining down when the radial position changed outwards.

After shutdown, the generated radionuclides would generate much decay heat which was the main source of waste heat. Compared with the nuclear heat deposition, the waste heat was a small amount and could be brought out by coolant circuit.

\section{Conclusion}

The total radioactivity of breeding blanket changed gently at the beginning of shutdown and the valve declined quickly after one year. When CFETR just shut down, the total radioactivity of breeding blanket was $6.61 \times 10^{19} \mathrm{~Bq}$. One year later, the total radioactivity declined to $2.34 \times 10^{19} \mathrm{~Bq}$. When cooling time reached ten years, the corresponding value was only $7.98 \times 10^{18} \mathrm{~Bq}$ which was $12.1 \%$ of initial value. For tritium breeding material, neutron multiplier material and structure material, until the cooling time come to 2.6 years, 25.2 years and 46.4 years, respectively, they could be remotely operated.

Based on the analysis, there wasn't highlighted safety issue existing in blanket design. As long as proper management for nuclear waste were adopted, accident would never happen. The activation calculation and analysis for CFETR tritium breeding blanket will be more accurate in the future as the geometric model is getting more detailed.

\section{References}

[1]. Song YT, Wu ST, Li JG, Wan BN, Wan YX, et al. (2014) Concept Design of CFETR Tokamak Machine. IEEE Transactions on Plasma Science 42(3): 503-509.

[2]. Baonian W, Ding S, Qian J, Li G, Xiao B, et al. (2014) Physics design of CFETR: determina-tion of the device engineering parameters. IEEE Transactions on Plasma Science 42(3): 495-502.

[3]. Zheng J, Liu X, Song Y, Wan Y, Li J, et al. (2013) Concept design of CFETR superconduct-ing magnet system based on different maintenance ports. Fusion Engineering and Design 88(11): 2960-2966.

[4]. Iida H, Khripunov V, Petrizzi L. ITER Nuclear Analysis Report. NAG-20101-06-17-FDR.

[5]. Chen Z, Feng KM, Zhang GS, Yuan T, Wang XY, et al. (2005) Activation calculation and environmental safety analysis for ITER test blanket module. Nuclear Fusion and Plasma Physics 25-33.

[6]. Waters LS (2002) MCNPXTM user's manual, version 2.4.0. Los Alamos National Laboratory Los Alamos, New Mexico.

[7]. Forrest RA (2007) FISPACT-2007: user manual. UKAEA Fusion, UKAEA FUS 534.

[8]. Qi-jie W, Kaiming F, Zhi C (2008) Activation calculation and analysis for Chinese ITER solid test blanket module. Nuclear Fusion Engineering and Technology 28(3): 223-227.

[9]. Jing-ru H, Yi-xue C, Guo-shu Z, Qi-xiang C (2011) Activation calculation analysis for the China $2 \times 6$ solid breeder test blanket module. Nuclear Fusion Engineering and Technology 31(4): 344-349.

[10]. Kaiming F (2000) Calculation of waste disposal rating for the fusion experimental breeder. Nuclear Fusion and Plasma Physics 2000(1): 15-22.

[11]. Cheng ET, Sze DK, Sommers JA, Farmer OT III (1992) Materials Recycling Considerations for D-T Fusion Reactors. Fusion Science and Technology 21: 2001-2008. 